\title{
ALCALINIZAÇÃO DO EFLUENTE LÍQUIDO ORIUNDO DO LAVADOR DE GASES DE UMA INCINERADORA DE RESÍDUO DE SERVIÇO DE SAÚDE: UM ESTUDO DE CASO
}

Janiny Souza Silva - janiny.silva@ hotmail.com

Instituto Federal de Educação Ciência e Tecnologia da Bahia - IFBA

Isabela Santos Aragão - aragaobela@ eambjr.com.br Instituto Federal de Educação Ciência e Tecnologia da Bahia - IFBA

Maira Caetano de Andrade - andrade.maira.2@gmail.com Instituto Federal de Educação Ciência e Tecnologia da Bahia - IFBA

Tamise Pereira Lima - limathamise2@ gmail.com

Instituto Federal de Educação Ciência e Tecnologia da Bahia - IFBA 


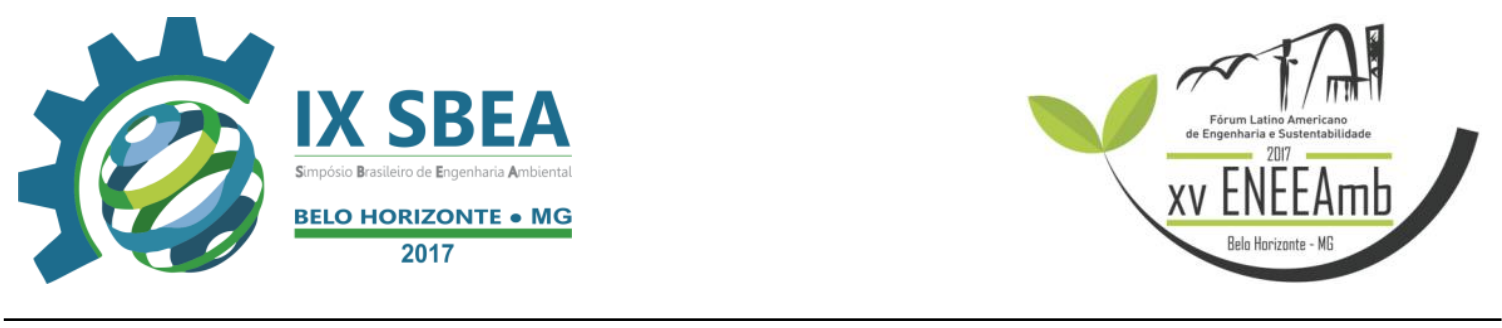

\section{RESUMO}

O processo de incineração é amplamente utilizado e recomentado, principalmente no tratamento de resíduos sólidos de saúde, pois esse método altera as características de periculosidade e patogenicidade do resíduo, reduzindo os impactos causados pelo seu descarte inadequado no meio ambiente. A queima dos resíduos gera gases que precisam ser devidamente tratados antes de serem lançados na atmosfera. Para o tratamento desse efluente gasoso, usa-se os lavadores de gases que tem como desvantagem a produção de um efluente líquido com característica ácida, podendo acarretar em problemas para às instalações, sendo necessárias medidas que minimizem esse efeito deletério.

Palavras-chave: efluente líquido, incineração, lavador de gases, mineração de carvão, resíduo cerâmico.

\section{INTRODUÇÃO/OBJETIVO}

Os incineradores de resíduos, também conhecido como usinas de queima, termovalorizadores ou usinas verdes, são aparelhos que tem por objetivo reduzir o volume dos resíduos, alterar as características de periculosidade e patogenicidade através do tratamento térmico. De acordo com a Resolução CONAMA nº 316 de 2002, o tratamento térmico ocorre quando o processo é submetido a temperaturas acima de oitocentos graus Celsius.

O tratamento térmico é um processo integrante da gestão de resíduos, sendo essa, definida como as atividades administrativas e operacionais envolvidas no manuseio, tratamento, acondicionamento, armazenamento e eliminação de resíduos, incluindo o transporte (WHO, 1999).

Atualmente, as mais diversas atividades antrópicas geram diversos tipos de resíduos que são classificados, quanto à origem, pela Política Nacional de Resíduos Sólidos, podendo ser resíduos domiciliares, sólidos urbanos, industriais, de mineração, de serviços de saúde, entre outros. Devido ao seu potencial de apresentar características biológicas, físicas e químicas perigosas, pode-se destacar os resíduos de serviço de saúde (RSS). Além do perigo de contaminação no ambiente ocupacional, os RSS, quando destinados de maneira incorreta, geram inúmeros impactos ambientais como a contaminação do solo e corpos hídricos. 


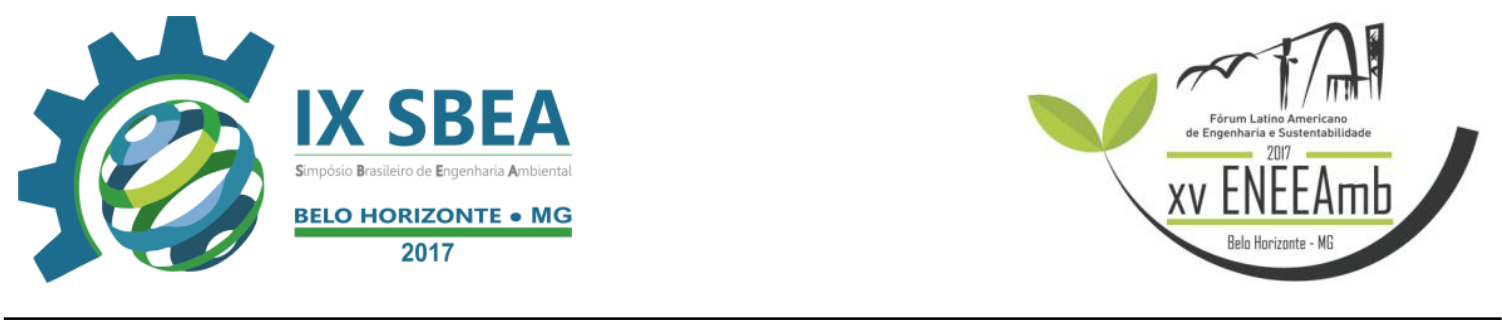

O gerenciamento dos RSS está sujeito ao disposto na Resolução RDC no 306 de 2004, que exige a elaboração de um Plano de Gerenciamento de Resíduos Sólidos de Serviço de Saúde (PGRSS), baseado nas características do resíduo gerado. Esta resolução prevê as etapas que devem estar contidas do PGRSS, dando especificações para cada uma delas. Na etapa de tratamento é indicado a incineração, podendo ser realizada no próprio estabelecimento gerador ou em ambiente externo por empresas terceirizadas. Em caso de tratamento externo, devem ser observadas condições de segurança para o transporte entre o estabelecimento gerador e o local de tratamento.

Além dos RSS, a incineração também é usada para eliminação de solventes e óleos não passíveis de recuperação, defensivos agrícolas e produtos farmacêuticos. Os requisitos de operação e os padrões de emissão de $\mathrm{HCl}, \mathrm{HF}, \mathrm{CO}, \mathrm{SO}_{2}, \mathrm{NO}_{2}$ e materiais particulados são normatizados pela NBR 11.175, que estabelece ainda o monitoramento contínuo e o teste de queima.

Apesar das vantagens da incineração, o processo de combustão apresenta desvantagens como a emissão atmosférica de substâncias como gases tóxicos, materiais particulados, metais pesados, dioxinas e furanos, além da geração de resíduos sólidos nocivos como as cinzas volantes. Alguns estudos apontam o prejuízo à saúde de comunidades localizadas no entorno de empresas incineradoras (Quina, Santos, Bordado \& QuintaFerreira, 2008; Gouveia \& Prado, 2010).

Diante disso, o sistema de incineração requer uma unidade de tratamento prévio de gases, para que estes sejam lançados em atendimento aos parâmetros estabelecidos pela legislação vigente, e as cinzas devem seguir para uma destinação adequada. Para minimizar as emissões atmosféricas dos contaminantes, pode ser utilizado um sistema de lavadores de gases, instrumentos que removem particulados e contaminantes gasoso através do contado direto com um liquido lavador. Há uma variedade de lavador de gases no mercado, como: o lavador de ar convencional (air washer), lavador tipo torre com enchimento (scrubber), ciclone úmido, ciclone úmido com ventilador, separador úmido tipo orifício, precipitador dinâmico tipo úmido e lavador de gases venturidro (Clezar, 1999).

O uso de lavadores de gases acarreta na geração de efluentes líquidos que são direcionados para as Estações de Tratamento de Efluentes ou reincorporados ao processo. 


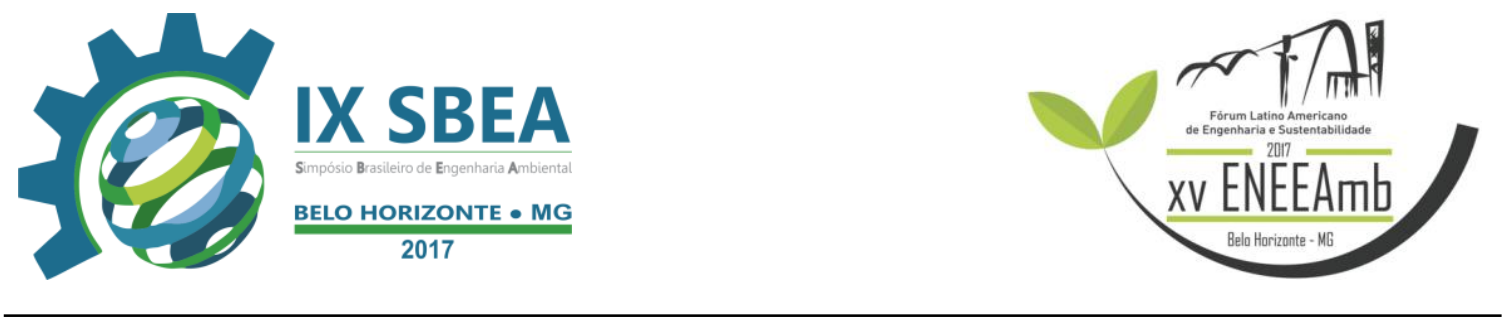

O efluente gerado no processo de lavagem dos gases oriundos da incineração de RSS apresenta característica ácida devido aos teores de enxofre e ácido clorídrico presente nesses resíduos. Durante as reações de combustão, tais substâncias surgem nos gases de combustão que são expelidos pela chaminé do incinerador. $\mathrm{O}$ baixo $\mathrm{pH}$ gera prejuízos para as instalações no equipamento de incineração e interrupções nos processos.

Desse modo, o presente trabalho, tem como objetivo apresentar propostas viáveis para elevar o potencial hidrogênio $(\mathrm{pH})$ do efluente de lavadores de gases de equipamentos de incineração de resíduos sólidos de saúde.

\section{METODOLOGIA}

O trabalho consiste em um estudo de caso com abordagem qualitativa e de natureza exploratória, envolvendo levantamento bibliográfico e documental (GIL, 2007). Fundamenta-se na descoberta das situações in loco e pela descrição do cenário das situações. Utiliza-se do estudo de caso para explorar o problema, sugerir novas formas de processo e trabalho, assim como compreender todo o processo de incineração e os aspectos e impactos ambientais decorrentes deste processo.

A empresa, na qual foi realizada o estudo, localiza-se no município de Vitória da Conquista - BA e possui cinco funcionários. Dentre esses, encontra-se Engenheiro Ambiental, operadores de incineração, motorista, auxiliar de coleta e higienização. A empresa recebe em média $23.425,33 \mathrm{Kg}$ de resíduos por mês, sendo esse valor distribuído entre resíduos de hospitais, postos de saúde, clínicas, farmácias e pet shops.

A empresa realiza os processos de transporte, acondicionamento e queima os resíduos de serviço de saúde (RSS). Inicialmente a bombona contendo os RSS é entregue nos locais de coletas. Uma vez que atinge o seu limite máximo, a mesma é transportada até a empresa incineradora, onde ocorre a pesagem da mesma. Após isso, as bombonas são acondicionadas até o momento de incineração do material coletado. Faz-se então a higienização da bombona que é então disponibilizada para uma nova coleta.

\section{RESULTADOS E DISCUSSÃO}




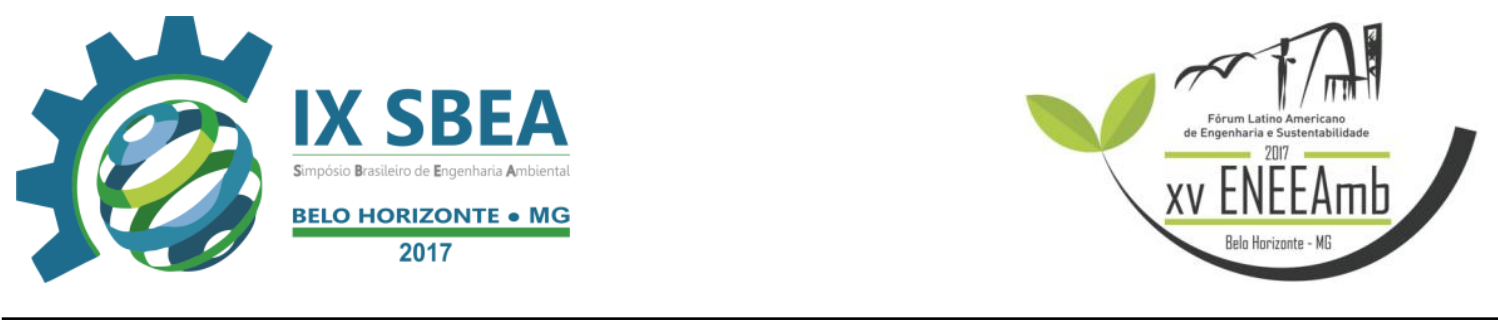

Os gases saem do incinerador com temperaturas na faixa de $800^{\circ} \mathrm{C}$ a $1000^{\circ} \mathrm{C}$. A empresa faz uso de lavadores de gases para a remoção de particulados e contaminantes gasosos, onde os mesmos são coletados pelo contato direito a um líquido coletor. Em razão da presença de cloretos, enxofre e nitrogênio na carga, o efluente proveniente dessa lavagem possui uma elevada acidez. Por se tratar de um ciclo fechado, este mesmo efluente é colocado de volta no processo e, assim, incinerado novamente sem nenhuma alcalinização prévia, gerando prejuízos às instalações. Como exemplo, tem-se chaminé do incinerador que precisa ser trocada com uma alta frequência, causando assim interrupções das atividades de queima. Além do problema econômico, esse reuso do efluente "bruto" pode gerar gases potencialmente tóxicos $(\mathrm{COx})$ devido à concentração de fluoretos e sulfetos.

Nestes tipos de empreendimentos, comumente, para se elevar o pH do efluente, é feita a adição de bases como hidróxido de sódio, sulfato de alumínio ou cal hidratada, porém, esses produtos já foram testados na incineradora em questão e acarretou em custos mais elevados do que a própria troca da chaminé, mostrando-se não-efetivo.

Barchinski (2011), propôs em seu estudo o uso de placas de resíduos sólidos submetidas à calcinação, gerados em Estação de Tratamento de Efluentes (ETE) de empresas de cerâmica, como material alternativo a ser empregado na etapa de alcalinização do efluente gerado no lavador de gases. Em seus resultados, Bachinski constatou a elevação do $\mathrm{pH}$ de 7,8 para 9,10 em um intervalo de tempo de 1 minuto e 30 segundos, após o tratamento do efluente com as placas calcinadas.

Além do resíduo de empresas de cerâmica, os rejeitos de mineração de carvão submetidos ao processo de calcinação também têm sido estudados como alternativa de alcalinização do efluente gerado na incineração. Geremias et al. (2008), constataram que esse tipo de rejeito pode proporcionar uma elevação do $\mathrm{pH}$ de 2,8 para 7,8. Essa capacidade de elevação estaria associada a presença de óxidos de metais $\mathrm{SiO}_{2}, \mathrm{Al}_{2} \mathrm{O}_{3}$ e $\mathrm{Fe}_{2} \mathrm{O}_{3}$ na sua composição, conferindo capacidade de promover a alcalinização do efluente. Os óxidos presentes seriam capazes de atuar como adsorvedores de íons de $\mathrm{H}_{3} \mathrm{O}^{+}$por mecanismos de adsorção química e física através de interação por complexação, formação de par iônico, troca iônica, interação eletrostática, forças de van der Walls entre outras, com consequente elevação do $\mathrm{pH}$. 


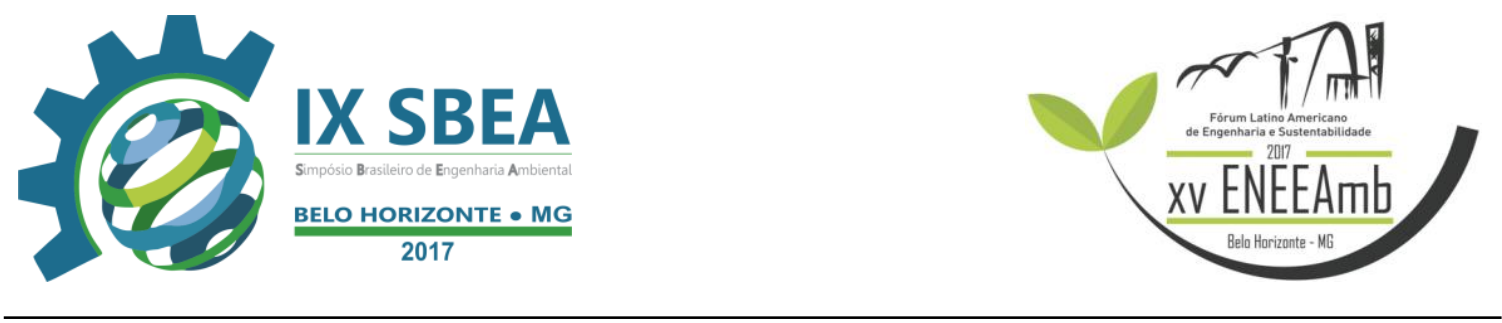

Os métodos supracitados podem ser considerados duplamente minimizadores de impactos, uma vez que além de tratar o efluente potencialmente tóxico gerado na lavagem, eles proporcionam uma destinação ambientalmente correta para os resíduos industriais. No caso da indústria de cerâmicas, o resíduo gerado é enquadrado, segundo a ABNT NBR 10.004, como resíduo Classe II A - não inerte e, portanto, potencialmente tóxico. Desse modo, o reuso destas placas se apresenta como uma importante ferramenta para sua valorização e minimização dos impactos ambientais negativos.

Além das alternativas citadas, tem-se o exemplo da técnica de adsorção, consistindo na remoção dos poluentes através da transferência entre os gases e superfície porosa de um material sólido. Os materiais mais utilizados são o carvão ativado, sílica gel e a alumina.

\section{CONCLUSÕES/RECOMENDAÇÕES}

A acidez do afluente oriundo dos lavadores de gases de equipamentos de incineração possui característica ácida que é prejudicial para as instalações e andamento do processo produtivo. $\mathrm{O}$ uso de rejeitos da mineração de carvão submetidos a um processo de calcinação ou de resíduos sólidos gerados na estação de tratamento de efluentes de empresas de cerâmicas podem ser uma estratégia para aumentar o pH desse tipo de efluente.

Sabe-se que o estado da Bahia possui, principalmente na região do recôncavo baiano, empresas de revestimento de cerâmica, assim como grandes mineradoras. Uma análise de viabilidade econômica deve ser considerada para que se estabeleçam parcerias de co-processamento. Sendo positiva a viabilidade financeira, pode-se então estabelecer uma parceria entre as empresas. Desta forma, o ganho ambiental seria duplo, pois seria designada uma destinação satisfatória aos resíduos tóxicos gerado nas empresas de revestimento de cerâmica e minimizaria a possível geração de gases tóxicos provenientes do reuso do efluente da lavagem de gases, além de uma economia financeira para ambas empresas.

Faz-se necessário, também, para tanto a realização de análises físico-químicas e testes em laboratórios, afim de evidenciar a efetividade desses resíduos na alcalinização 


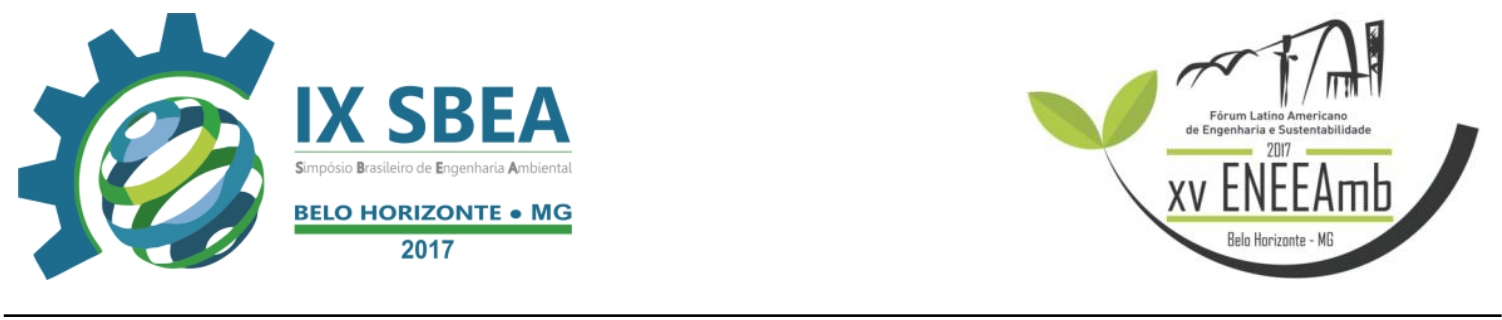

do efluente gerado na lavagem e definir quais dos métodos apresentados possui um melhor custo-benefício.

\section{REFERÊNCIAS BIBLIOGRÁFICAS}

ABNT. Associação Brasileira de Normas Técnicas. -NBR 11.175 Incineração de resíduos perigosos - padrões de desempenho. Rio de Janeiro, Brasil.

ABNT. Associação Brasileira de Normas Técnicas. -NBR 10.004 resíduos sólidos classificação. Rio de Janeiro, Brasil. 2004b.

BARCHINSK, R. da S. et al. Aproveitamento de Resíduos Sólidos de Estação de Tratamento de Efluente de Indústria de Revestimentos Cerâmico para a Alcalinização de Efluentes Gerados em Lavadores de Gases. Cerâmica Industrial, 2011.

BRASIL. Conselho Nacional de Meio Ambiente. Resolução no 316/2002. Disponível em http://www.mma.gov.br/port/conama/res/res02/res31602.html. Acesso 11 jan. 2017.

BRASIL. (2010) Lei $\mathrm{n}^{\circ}$ 12.305, de 2 de agosto de 2010. Institui a Política Nacional de Resíduos Sólidos; altera a Lei $n^{\circ}$ 9.605, de 12 de fevereiro de 1998; e dá outras providências. Brasília.

CLEZAR, C. A. et al. Ventilação Industrial. Florianópolis: UFSC, 1999. 298 p.

GEREMIAS, R. et al. Use Of Coal Mining Waste For The Removal Of Acidity And Metal Ions Al (III), Fe (III) And Mn (II) In Acid Mine Drainage. Environmental Technology, v. 29, p. 863-869, 2008. PMid:18724641. http://dx.doi.org/10.1080/09593330802015409

GIL, Antônio Carlos. Métodos e técnicas de pesquisa social. São Paulo: Atlas, 1989.

GOUVEIA, N., Prado, R.R. (2010). Analise espacial dos riscos a saúde associados a incineração de resíduos sólidos: avaliação preliminar. Revista Brasileira de Epidemiologia, 13(1), 3-10. 

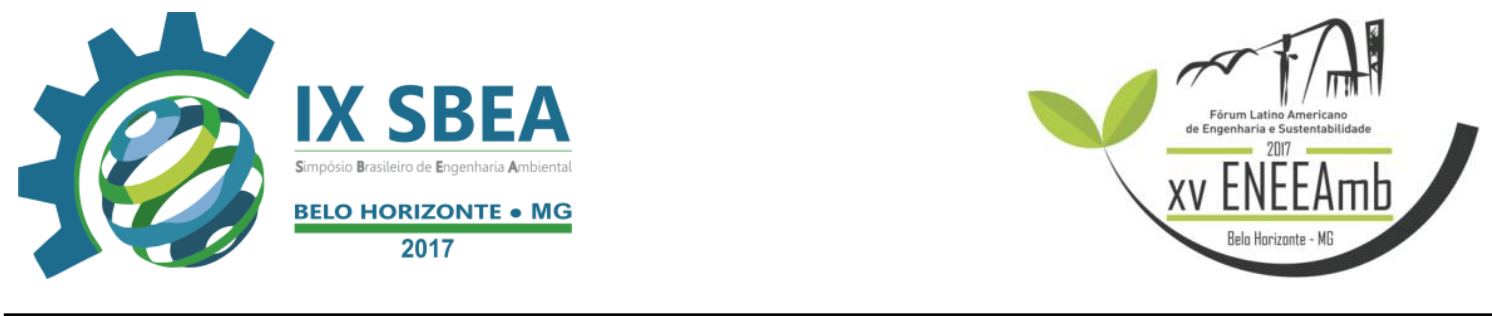

Ministério da Saúde Agência Nacional de Vigilância Sanitária: RESOLUÇÃO RDC No 306, DE 7 DE DEZEMBRO DE 2004. Disponível em http://bvsms.saude.gov.br/bvs/saudelegis/anvisa/2004/res0306_07_12_2004.html__Acesso 11 jan. 2017.

Politica Nacional de Resíduos Sólidos. Disponível em: http://www.planalto.gov.br/ccivil_03/_ato2007-2010/2010/lei/112305.htm. Acesso em 02 abril 2017.

QUINA, M.J, Santos, R.C, Bordado, J.C, Quinta-Ferreira, R.M. (2008). Characterization of air pollution control residues produced in a municipal solid waste incinerator in Portugal. Journal of Hazardous Materials, 152, 853-869.

WHO. World Health Organization. (1999). Safe management of wastes from healthcare activities. Geneva. WHO Library Cataloguing-in-Publication Data. 